\section{Cultura e Extensão em um Instituto de Pesquisa: as Experiências e Propostas do Instituto de Medicina Tropical de São Paulo}

\author{
Culture and Universitary Extension in a Research Institute: \\ the Experiences and Proposals of Tropical Medicine \\ Institute of São Paulo
}

\section{RESUMO}

Institutos de pesquisa em geral têm um contato distante com a sociedade e relegam a um plano secundário as atividades de extensão. No Instituto de Medicina Tropical de São Paulo, desde a sua fundação, houve inúmeras tentativas de atividades de extensão pelo tipo de pesquisa desenvolvido. Mas, num instituto de pesquisa, a manutenção destas atividades é um desafio e ocorrem frequentes interrupções. Neste artigo, procuramos mostrar as novas iniciativas para aumentar a interface do IMTSP com a sociedade "laica" e detectamos que a conscientização do corpo próprio e o "aggiornamento" dos conceitos de extensão são muito benéficos para os institutos de pesquisa. Contradizendo a suposição inicial limitada de uma transmissão unidirecional de conhecimento à sociedade e um plano secundário para as ações de extensão, propõe-se aqui que estas são mais valiosas para mostrar o reconhecimento da sociedade e ratificar o valor da pesquisa desenvolvida nos institutos de pesquisa, como o IMTSP.

Palavras-chave: Instituto de Pesquisa. Sociedade. Conscientização. Extensão. Mistério.

\section{ABSTRACT}

Usually, research institutes presented a distant relationship with the laic Society. This fact results in an undervaluation of activities of social promotion or communication. In the Instituto de Medicina Tropical de São Paulo, since our foundation there were several actions for social promotion and communication, due to our research type or open field projects, but with challenging and difficult maintenance with frequent interruptions, as a research institute. Here, we present the new initiatives to enhance the interface between Society and IMTSP and we detect that the awareness of scientific staff and the "aggiornamento" of concepts and interactions were extremely beneficial to research institutes. Contradicting the initial thinking of a limited unidirectional
HEITOR FranCO de

ANDRADE JÚnior

Universidade de São Paulo. Faculdade de Medicina, São Paulo, Brasil

LUCIANA REgina

MEIRELES

Universidade de São Paulo. Instituto de Medicina Tropical de São Paulo, São Paulo, Brasil 
knowledge transmission of those contacts and a "downstairs" social promotion or communication, those initiatives were more important to the scientific staff by showing the Society commitments with the support of the research, ratifying the value of the evolving research in those institutes.

Keywords: Research Institutes. Society. Awareness. Promotion. Mistery.

\section{COMO COMEÇARAM AS ATIVIDADES DE CULTURA E EXTENSÃO NO INSTITUTO}

O Instituto de Medicina Tropical é um instituto especializado de pesquisa da USP, voltado para o estudo das doenças tropicais e saúde internacional. Basicamente, estamos preocupados com a transmissão das doenças entre regiões e como isto pode ser prevenido e contido de forma segura. Antes do século XX, não havia sistemas nacionais de saúde e ocorria uma ampla migração de pessoas doentes para os grandes centros, como São Paulo, na procura de tratamento. Estes indivíduos vinham de diferentes regiões, portando doenças das mais variadas, tanto brasileiras como exóticas. Para seu tratamento havia a necessidade de conhecimentos enciclopédicos tanto clínicos como laboratoriais. O Instituto de Medicina Tropical de São Paulo (IMTSP) foi criado há mais de 50 anos para cuidar das doenças tipicamente brasileiras, como a doença de chagas e a paracoccidioidomicose, e prover meios e sistemas para disseminar seus tratamentos e prevenções. Além de reagentes e diagnósticos, também desenvolvemos estudos sobre tratamento, descoberta de agentes infecciosos e eficiência de vacinas. Simplificando, o IMTSP é um instituto de pesquisa voltado para o estudo das doenças e seus agentes, sem tratar diretamente o doente.

As primeiras atividades de extensão dos serviços à comunidade e a interação com a sociedade não foi feita por uma graduação convencional, como na maioria das unidades da USP, nas quais os alunos, de certa forma, representam a sociedade, mas apenas por cursos de especialização de formação de amplificadores de conhecimentos.

Desde a sua criação, já no próprio prédio, havia uma preocupação de interação com a sociedade. As doenças que estudamos são menos conhecidas e frequentemente estigmatizadas, como a hanseníase, a "xistosa" ou a "maleita". O conhecimento do público era incipiente e não havia sistemas de transmissão de informação em massa. Naquela época, os médicos não eram muitos e não dispunham de tempo e oportunidade para conversar com o paciente, estabelecendo-se uma relação típica de médico sábio salvando o passivo paciente.

A Medicina Tropical interagia diretamente no atendimento pelo posto de saúde e pela comunidade, já que pretendia sanar as formas mais grosseiras de transmissão, e não é difícil imaginar que escritores, como Monteiro Lobato, tenham se preocupado em divulgar ao leigo a importância de medidas simples, como o uso de sapatos, no famoso livreto do Jeca Tatú. As noções de higiene pessoal eram transmitidas por professoras dedicadas que pressionavam as mães e as famílias para melhor qualidade de higiene. 
O fundador e idealizador do IMTSP, Carlos da Silva Lacaz, não era imune à interação com a sociedade. Quando da construção do primeiro prédio, preocupou-se em criar espaços de visitação e até um museu com peças de cera, artisticamente criadas por Augusto Esteves e Waldomiro Siqueira (Figura 1), para representar os doentes portadores de doenças tropicais, já que a visita dos leigos às enfermarias era inviável pelo preconceito e pelo risco de transmissão. Havia visores que permitiam aos visitantes observar o trabalho dos pesquisadores e técnicos. Nesta ocasião, foi criada a Revista do Instituto de Medicina Tropical.

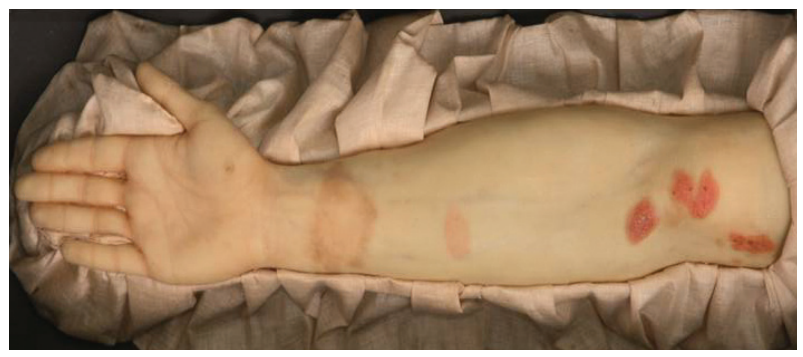

Figura 1 - Braço com lesões eczematosas. Ceroplastia de Augusto Esteves e imagem de Gregor Osipoff. Fonte: Acervo do Museu Histórico da FM-USP.

Além disso, com seus colegas, o professor Lacaz providenciou um curso de especialização que foi o formador de especialistas por mais de 30 anos, gerando doutores e especialistas que contribuíram para a formação de mais cientistas na área. Isto foi uma reação em cadeia e é mais ou menos lógico que a evolução numérica dos especialistas e do conhecimento levasse a novas definições como a infectologia, a epidemiologia e a medicina preventiva, também resultando em subdivisões da Universidade para o ensino da graduação em Saúde; em especial, os Institutos de Ciências Biomédicas, ou de Ciências da Saúde, hoje perfeitamente aceitáveis para o ensino de microbiologia, parasitologia, imunologia e farmacologia. Tudo isto evoluiu e fomos eficientes no controle da maioria das doenças infecciosas, que deixaram de causar grande mortalidade apesar da elevada morbidade, graças ao esforço das pesquisas da Medicina Tropical [1]. Este sucesso efetivo com medicamentos e vacinas levou a um direcionamento das linhas de pesquisa dos institutos mais especializados para a ciência das doenças crônico-degenerativas, hoje, reforçando a necessidade da existência do IMTSP como instituto de pesquisa abrangente nas doenças de transmissão por pessoas, produtos e agentes que, com a globalização, deixaram de ser apenas brasileiras, tornando-se mundiais, envolvendo segurança sanitária dos países, ou seja, a saúde internacional.

Desde a sua fundação, as atividades de contato e interação com a sociedade eram parte intrínseca das ações dos vários pesquisadores do IMTSP, já que estavam frequentemente envolvidos em pesquisas de campo, onde necessitavam interagir com a sociedade para que seus projetos fossem bem executados, possibilitando o controle ou até mesmo a erradicação de uma determinada doença tropical. Em especial, a professora Judith Kloetzel era preocupada com estes aspectos e sempre que possível trazia para o laboratório o contato com o público, mas a própria dinâmica e 
complexidade do laboratório não favoreciam este tipo de interação, já que as doenças tropicais são, em geral, de fácil transmissão. Assim, estas pequenas iniciativas foram ao longo do tempo sendo abandonadas.

Entre 1990 e 2000, não ocorreram interações significativas de extensão à comunidade no IMTSP, visto que a instituição estava em reorganização administrativa. Poucas iniciativas, como as do professor Amato Neto, foram isoladas e restritas em aulas ou seminários. Lógico que a produção científica foi mantida pujante, mas este período gerou uma inércia muito comum nos meios científicos, de poucas atividades de extensão à comunidade, com escusas do tipo "não seremos compreendidos", "tudo é muito complicado", etc. Além disso, a ausência de uma graduação formal levou os docentes e pesquisadores do IMTSP a se afastarem de graduações próximas, como a graduação em Medicina da FMUSP, distanciando ainda mais um excelente corpo técnico e cientistas da sociedade.

Nesse período o mundo estava mudando, assim como a ciência. Tanto os alunos estavam diferentes, não mais voltados apenas para o texto escrito, mas muito mais visuais, como havia uma evolução na pesquisa científica, principalmente em seus aspectos éticos. O IMTSP foi imediatamente responsivo, com a primeira Comissão de Ética do complexo do Hospital das Clínicas e Faculdade de Medicina da USP, graças aos esforços da professora Maria Carolina S. Guimarães [2], mas só isto não bastava, nós precisávamos encontrar a sociedade e nos redescobrirmos.

Com sistemas de informação eficientes como a internet e a televisão interativa, não estamos mais diante de pequenas experiências visuais, como no Sítio do Pica-pau Amarelo na TV Tupi, e sim com um público-alvo muito maior e consciente. A ciência deixou de ser um sistema de poucos sábios para atingir grandes frações da população brasileira. Programas mundiais de divulgação científica como o Mundo de Beakman (Columbia Pictures) trouxeram pela televisão o raciocínio científico para todos os lares e os seriados passaram a mostrar detalhes científicos em ciência forense. O DNA virou identificação mesmo que ninguém saiba do que é feito, ou como é sua sequência. A informação tornou-se disponível para todos através da internet e meios de comunicação. Parte do conhecimento que era apenas transmitido na graduação passou para os níveis intermediários de ensino e o maior conhecimento de línguas "universais" como o inglês trouxe acesso às informações globais. Cada pessoa passou a aprender mais e ter acesso a mais informações, mas, ainda, temos que digerir estas novidades. Surgem conceitos de aldeia global e, também, são criadas redes sociais como Orkut, Facebook e Twitter. A informação está disponível, mas o espírito crítico para interpretá-la não. Nesse ponto, a qualidade da imprensa vista, falada ou escrita é essencial. Antes, as revistas de divulgação científica, como a clássica Scientific Ameri$c a n^{\mathrm{Ta}}$, eram destinadas ao público cientifico de outras áreas. Assim, médicos liam sobre engenharia e biólogos sobre militares, mas o nível de informação era mantido dentro da "intelligentsia" científica. Os artigos eram excelentes e criteriosos e a evolução natural do processo foi alcançar o público leigo com revistas, como a Superinteressante (Editora Abril, São Paulo), com excelente documentação visual, ou até mesmo criar programas ou seções científicas em jornais e na programação televisiva. Isto aumentou muito a necessidade da confirmação da qualidade do conhecimento, passando a 
serem frequentes as consultas e entrevistas para estas formas de comunicação. Mas nem toda imprensa é responsável e a necessidade de "venda" do produto "informação científica" passou a ser prioritária e não sua veracidade. Surgiram "especialistas" televisivos e suas vozes passaram a ser verdade.

A Universidade não podia permitir isso porque uma de suas atribuições sociais é ser a reserva técnica do conhecimento cientifico. Os pesquisadores do IMTSP também sentiram a necessidade de passar para a comunidade uma informação mais sólida e foram reiniciadas as atividades de extensão.

\section{COMO É HOJE A EXTENSÃO NO IMTSP}

A extensão foi uma oportunidade interessante para se criar um espírito crítico e a formação de um corpo especializado em atividades direcionadas à comunidade. Assim, a partir de 2000, as atividades de extensão tiveram início pelo seu próprio grupo de funcionários que começaram a desenvolver ações comunitárias em escolas e associações, iniciando uma atividade nova de extensão. Com a evolução do IMTSP para unidade da USP, a administração do Instituto notou a necessidade de incluir as atividades de extensão na unidade e foi proposto, pelo autor do artigo, um curso para leigos voltado para a saúde em viagens; na realidade, mais focado para o público da terceira idade. $\mathrm{O}$ objetivo não era só o curso em si, mas também que os funcionários falassem de suas atividades para leigos. A escolha dos temas e dos palestrantes foi proposta por discussões entre o corpo próprio do IMTSP. Falar de saúde em viagens foi mercadológico, já que o Instituto sempre foi voltado ao "doente" e era preciso inverter a situação para a promoção da "saúde", visando à manutenção da saúde e não o tratamento de doentes. O tema era novo, mas chegava ao contexto moderno da expansão de viagens e rapidamente foi abraçado pelo corpo próprio, que dividia as tarefas, mas também dividia conhecimentos e trocas de informações. Havia a discussão de como fazer as atividades, e habilidades novas foram descobertas. Para facilitar e disseminar o curso, novos coordenadores e palestrantes eram propostos a cada versão. O público das primeiras versões foi maior que o esperado, e não só de terceira idade, mas muito mais leigo e de participação geral. Destas interações, foi possível estabelecer uma identidade com a segurança sanitária, outra evolução da forma de expressão, mantendo os objetivos científicos da instituição, mas com uma nova forma de atualização ou "aggiornamento". As novas tecnologias didáticas foram rapidamente absorvidas e vídeos e outros meios de comunicação foram disponibilizados para alunos e professores. Meios de divulgação e cronogramas de execução e desempenho apareceram e foram integrados pelos vários coordenadores. Um aspecto essencial era a constante renovação de palestrantes e temas com abertura para inclusão de novos conteúdos em cada versão, o que gerava uma multiplicidade de cursos e versões, mostrando a capacidade didática existente e até então pouco usada no IMTSP.

Como retorno do sucesso das primeiras edições, fomos convidados a ministrar palestras sobre saúde em viagens em várias unidades do SESC-SP com programação específica para a terceira idade. Assim, os autores do artigo realizaram palestras 
nas unidades de São José do Rio Preto, Santos e Capital. A experiência advinda desta atividade foi ímpar, pois a troca de informações com um público experiente, como o da terceira idade, abriu a perspectiva de inclusão de novos temas, como "Seguro viagem", na programação do curso regular do IMTSP.

Com os cursos de extensão, foram adquiridos objetivos de divulgação mais claros e isto permitiu diretamente o oferecimento de disciplinas nucleares para a graduação em Turismo da ECA-USP, que nessa época estava em renovação de seu programa de graduação. Com a concretização das metas e dos docentes, várias ações evoluíram a partir deste curso e uma melhor visão da instituição pelo seu corpo foi consolidada.

Quanto ao público discente, em graduação ou leigo, ficou claro que a interação a cada versão aumentava a abrangência dos cursos de difusão, ou disciplinas, com uma nova visão do que devia ser ministrado. A didática de aulas complexas foi testada de várias formas até se chegar a uma forma mais agradável para leigos sem perda de conteúdo. A própria conceitualização do que era o IMTSP foi revista a partir das opiniões dos alunos, que comentavam aspectos importantes da instituição, antes esquecidos. A apresentação e discussão da identidade da instituição com a sociedade em cursos de difusão foram essenciais para sensoriar a nossa inserção social, em especial, pelo fato de não dispormos de um curso formal de graduação. Imaginar que não ocorre interação em cursos de difusão, de que a informação é unidirecional do professor para o público, é ignorância de quem não ministra estes cursos. O público discente de difusão é interessado, interessante e mais responsivo às interações do que outros públicos da universidade, ligados a objetivos mais claros como a graduação e pós-graduação.

Uma vez estabelecida a necessidade de atividades de extensão na instituição, uma proposta promissora de interação do IMTSP com a comunidade fora de suas instalações resultou de uma atividade de pesquisa com escolares. A pesquisa de saúde em escolas é complexa e muito controlada em seus aspectos éticos. Uma atividade interativa de coleta de saliva em alunos do ensino fundamental do extremo leste de São Paulo foi feita utilizando um trabalho motivacional para retribuir a coleta com conhecimento. Nesse momento, foram elaborados, pelo corpo próprio, em especial, a autora do artigo, vários materiais voltados para a prevenção da transmissão de doenças por via oral para crianças, com atividades audiovisuais e impressas. $\mathrm{O}$ resultado foi fantástico e os pós-graduandos envolvidos auxiliaram na construção, execução e monitoria da intervenção.

Por promoção do corpo técnico, também foi criada uma exposição de pôsteres com as principais doenças tropicais e suas prevenções, que foi exposta em estações do Metrô de São Paulo e apresentada a várias escolas públicas. Na ocasião, a recém-criada pós-graduação do IMTSP não tinha atividades de extensão, e em um de seus primeiros eventos promoveu a exposição de pôsteres individuais, onde cada pós-graduando apresentou seu trabalho e foi avaliado por seus pares, numa interação entre grupos muitos distantes, já que a Medicina Tropical é praticamente enciclopédica.

Em 2010, o IMTSP entrou em contato com o Museu de Ciências da USP e participou, no ano seguinte, da Feira de Ciências no Parque CienTec, um parque extremamente interessante da Universidade e um local a ser melhor explorado para extensão. Nesta primeira participação, levamos apenas a exposição do Metrô e filmes interativos 
e, embora tivéssemos material de divulgação, a exposição foi pouco interessante para o público da Feira de Ciências, composto por estudantes de ensino fundamental e médio. Alguns aspectos ficaram claros, como a necessidade da presença física do monitor, essencial para uma exposição, já que a interação e o diálogo com o especialista facilita a fixação dos conhecimentos. Após esta primeira experiência, planejamos envolver mais pós-graduandos e o corpo técnico para a próxima Feira, em 2012 (Figura 2). Sob a direção da autora do artigo, foi criado, pelos pós-graduandos e pela seção de programação visual do IMTSP, um vídeo sobre DNA e sua purificação e um vídeo sobre microrganismos patogênicos. Além disso, material didático e esquemas para as diferentes idades foram preparados pelos pós-graduandos, sempre visando à participação direta dos visitantes. Quando da apresentação, a presença dos alunos da pós-graduação que foram "atores" dos vídeos educativos, além das demais experiências, geraram a curiosidade e a participação de centenas de crianças e adolescentes no nosso estande nos vários dias de exposição. Na ocasião, vários erros puderam ser corrigidos. Um dos vídeos era muito longo e as expressões chatas e difíceis foram removidas das conversas e um diálogo claro entre pós-graduandos, funcionários e visitantes se estabeleceu com facilidade.

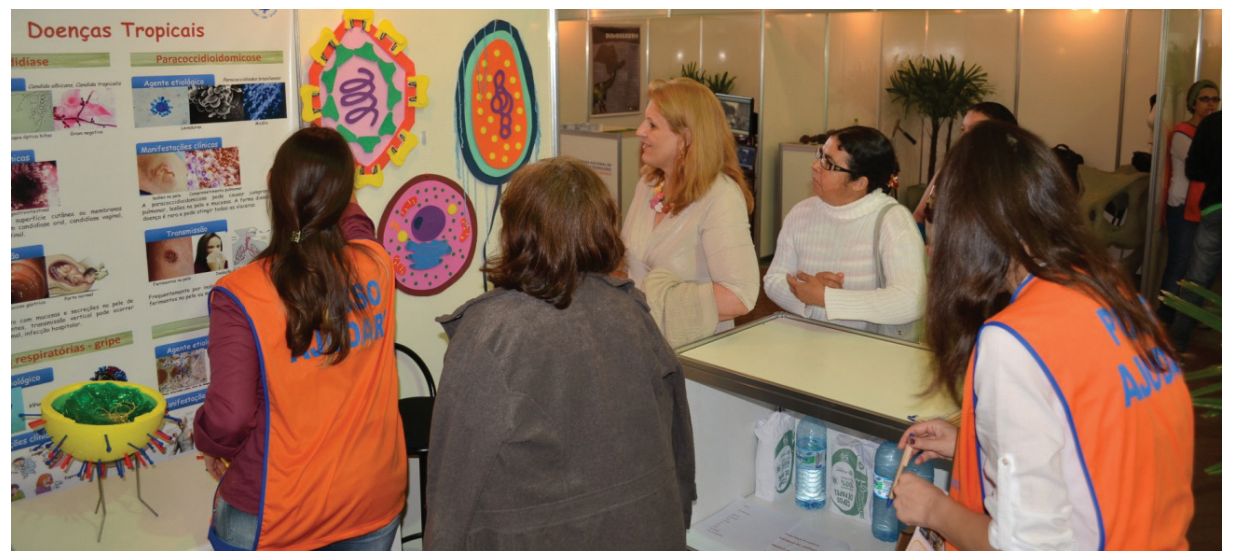

Esta participação se renovou em 2013 e acordos foram firmados para que estas atividades constassem créditos no programa de pós-graduação do IMTSP, premiando a participação dos pós-graduados. Nesse ano, além das atividades anteriores, modelos de agentes infecciosos foram montados e puderam ser manuseados pelos visitantes, e eles puderam participar também de coletas entomológicas com a construção de armadilhas para insetos no recinto da Feira. $\mathrm{O}$ entusiasmo e o treinamento dos monitores foram essenciais para o sucesso das atividades no estande. Cada feira deve ser encarada como uma nova atividade, mesmo que use as experiências de edições anteriores. Existe a necessidade de constante renovação de vídeos, materiais e monitores. Estes últimos devem ter participado ativamente da elaboração do material didático, para não ser apenas um repetidor das informações, o que é notado e rejeitado pelo público. Isto talvez ocorra com exposições mais caras e amplas que vão sendo
Figura 2 - Estande do IMTSP na Feira de Ciências, realizada no Parque CienTec em 2012. Créditos: Luciana Regina Meireles. 
progressivamente abandonadas pelo público alvo, já que são muito mais consolidadas pelo seu porte e custos. Exposições e interações menores são mais ágeis, acessíveis e menos propensas a uma esclerose ou esgotamento.

Nossa experiência mostra que o contato com o público, quer seja em cursos de difusão, ou em feiras, depende de treinamento prévio para uma boa interação com a sociedade. Parece estranho dizer que o treinamento começa exatamente quando planejamos e ministramos um curso, ou uma exposição, mas esta é a única forma efetiva de obtermos sucesso nos eventos seguintes. A primeira linguagem vai sendo substituída por formas mais acessíveis, as aulas são reformuladas e o corpo docente é treinado até que haja fluência.

\section{PERSPECTIVAS PARA O IMTSP E PARA A USP}

A proposta atual do IMTSP é a manutenção das atividades desenvolvidas nos últimos anos, oferecendo curso de difusão dentro e fora da USP e participando de feiras e eventos de intervenção isolados. A ideia é a construção de múltiplas e pequenas exposições itinerantes, capazes de serem montadas em escolas públicas ou ambientes menores, permitindo pequenas intervenções em escolas. Isto levaria o conhecimento de forma mais disseminada e poderia resultar em barateamento do custo das exposições. Para tanto, a exposição deve ser de fácil montagem e preparação, levando o conhecimento sobre temas variados. Nas escolas públicas, a pretensão é a de duas visitas por escola, uma de preparação com o corpo docente local e outra de execução da intervenção. Nossa experiência na zona leste mostra que a intervenção é muito marcante para as crianças, sendo que os conceitos são lembrados com facilidade após um ano da exposição, com valorização do corpo docente local.

As outras perspectivas de extensão cultural do IMTSP são interessantes e estão voltadas mais para a saúde internacional e acesso a informações pela internet. Como estamos envolvidos com o controle das doenças transmissíveis e promoção da saúde pública nas várias regiões, no futuro, estas doenças estarão vinculadas à exposição a novos ambientes, ou situações, e não serão doenças meramente comuns. Será necessário todo o esforço para o reforço da higiene e segurança sanitária, a fim de prevenir a reintrodução ou reemergência destas doenças em nosso meio, principalmente para os jovens, que estarão distantes de tempos onde estas enfermidades eram mais frequentes. A ideia é somar esforços e produzir material audiovisual de livre acesso e fácil visualização pela internet, através de vídeos com menos de cinco minutos de duração que sejam de fácil assimilação pela população.

Neste contexto, é interessante ressaltar algumas questões importantes referentes à cultura e extensão. $\mathrm{O}$ treinamento dos docentes nas atividades de extensão não deveria ser apenas voluntário, pelo contrário, a universidade deveria investir em cursos à distância de curta duração que mostrassem o potencial da extensão ao seu corpo docente, diminuindo a rejeição a estas ações. Além disso, não podemos esquecer que a voluntariedade pode levar a vieses, já que os interessados em atividades de extensão são frequentemente propensos a questões políticas, ou com visão muito pessoal de 
interação. Como a USP tem grandes proporções, haveria a necessidade de criação de materiais audiovisuais para uso comum, como vídeo de apresentação da Universidade ou até mesmo de cada uma de suas unidades, que deveriam ser disponibilizados a todos os seus docentes e especialistas para atividades de extensão.

O sensoriamento do impacto social de cada ação de uma unidade, através de cursos de difusão ou atividades semelhantes, deveria ser anual para permitir sua valorização. A interação com museus e parques da USP seria uma maneira de permitir que estes locais tenham espaço para atividades de outras unidades da Universidade, permitindo uma interação com o público que beneficiaria tanto os museus e parques como as unidades e institutos especializados. A interação deve ser curta e pontual para que não ocupe espaços de forma definitiva, não consuma tempo excessivo do docente ou pesquisador, e seja constantemente renovada e dinâmica.

As experiências de extensão universitária do IMTSP com cursos de difusão, exposições em feiras de ciências e outras interações com a sociedade foram importantes para mostrar novos objetivos para a instituição, conscientizar seu corpo próprio e, principalmente, rejuvenescer conceitos estabelecidos, mostrando que estas ações são muito mais benéficas para a instituição do que a suposição apenas de uma transmissão unidirecional de conhecimento à sociedade.

\section{REFERÊNCIAS}

[1] BARRETO, M.L.; TEIXEIRA, M.G.; BASTOS, F.I.; XIMENES, R.A.; BARATA, R.B.; RODRIGUES, L.C. Successes and failures in the control of infectious diseases in Brazil: social and environmental context, policies, interventions, and research needs. Lancet, v.28, n.377 (9780), p.1877-1889, 2011. Disponível em: <https://repositorio.ufba.br/ri/bitstream/ri/3026/1/Per\%20int\%202011.11.pdf>. Acesso em 30 set. 2014.

[2] GUIMARAES, M. C. S. Diretrizes éticas para pesquisas em sujeitos humanos financiadas pela FAPESP: Grupo de Bioética e Pesquisa Populacional. São Paulo Medical Journal, v.112, n.4, p. 627-628, 1994. Disponível em: <http://www. scielo.br/scielo.php?script=sci_arttext\&pid=S1516-31801994000400001>. Acesso em 30 set. 2014.

HEITOR FRANCO DE ANDRADE JR professor associado do Departamento de Patologia da Faculdade de Medicina da Universidade de São Paulo-e-mail: hfandrad@usp.br

luciana Regina meIReles especialista do Instituto de Medicina Tropical de São Paulo da Universidade de São Paulo - e-mail: lrmeirel@usp.br 